\title{
Commentary \\ Advanced directives and treatment decisions in the intensive care unit
}

\author{
Leslie M Whetstine
}

Philosophy and Bioethics, Walsh University, 2020 E. Maple Street, NW, North Canton, OH 44720, USA

Corresponding author: Leslie M Whetstine, Lwhetstine@walsh.edu

Published: 26 July 2007

This article is online at http://ccforum.com/content/11/4/150

(c) 2007 BioMed Central Ltd

See related review by Tillyard, http://ccforum.com/content/11/4/219
Critical Care 2007, 11:150 (doi:10.1186/cc5971)

\begin{abstract}
Prospective medical decision-making through the use of advanced directives is encouraged and frequently helpful in guiding treatment for the critically ill. It is important to recognize the attendant shortcomings when using such tools in clinical practice.
\end{abstract}

In this issue of Critical Care, Tillyard [1] explores whether advanced directives are effective at guiding treatment decisions for incapacitated patients. Tillyard concludes that although advanced directives should ideally improve decisionmaking, this frequently does not translate effectively at the bedside.

Studies have shown that, in themselves, advanced directives are insufficient to withstand the complexities of end-of-life care [2,3]. To resolve this divide between theory and practice, however, it is helpful to refocus the issue. We ought not to be overly concerned with the execution and application of advanced directives but with the motivation behind them and the dialogue they engender over time [4].

In the United States, advanced directives are used as a blanket term that can refer either to a living will or a durable power of attorney, two distinct methods designed to safeguard autonomous choice. A living will is a written document that expresses a preference for or against specific types of treatment; it typically becomes effective only when the patient is incompetent and either terminally ill or permanently unconscious. A durable power of attorney is a document that empowers an individual surrogate (appointed by the patient) to assume decision-making authority as soon as the patient loses decisional capacity.

Used independently of durable powers of attorney, living wills are seldom helpful, for a number of reasons. Unless individuals have already been diagnosed with a particular illness and been informed of the prognosis, it is difficult for them to predict what their future holds; that is, what kind of illness/injury they will suffer and what types of medical interventions they must consider [5]. Because medicine is not static, making a prospective determination regarding the types of treatment one would want in the future is difficult. The quality of life that patients may find intolerable while healthy is apt to change when options are limited between choosing a compromised life or choosing death; thus, the psychological transition that an individual will undergo when faced with such choices is heavily nuanced and cannot be accurately predicted in advance [6]. Further, living wills tend to be inflexible in that they express a preference but do not offer any supporting rationale, thus leaving little room for interpretation or authentic knowledge of the individual.

The bioethics literature suggests that it is best to combine a living will with a durable power of attorney to ensure a comprehensive approach to future decision-making. In this regard an informed surrogate can adjust to changing circumstances and maintain a collaborative relationship with the health care team while promoting the patient's particular value system and respecting the individual's autonomy.

Despite the fact that the United States is known for supporting an assertive vision of autonomy and has witnessed the importance of advanced decision-making played out in the media (for example the Schiavo case), a relatively small percentage of Americans complete advanced directives, as Tillyard notes. The reasons for this may be multifactorial, ranging from the demands of managed care in which the doctor-patient relationship has been undercut by the consumer-driven market, to the fact that in the United States there is disparate access to health care: one-quarter of the population is uninsured or underinsured. Other reasons for individuals not availing themselves of the opportunity to complete or even discuss advanced directives may include fear, ignorance or a false sense of security that their family will 
make the best decision. This is perhaps the most dangerous presumption because data indicate that family members rarely make decisions that the patient would make if competent, and the potential for conflict and guilt among family members is great [7].

Notwithstanding their limitations, however, advanced directives are invaluable tools that should be encouraged, not as ends, but as a means to further communication between patient, physician and family. Creating a living will and/or choosing a surrogate through a durable power of attorney should not be an isolated event broached during a time of acute crisis but should be part of an ongoing discussion intrinsic to the doctor-patient relationship. Establishing why rather than whether the patient accepts or rejects treatments gives insight into the individual's world view and best safeguards autonomous choice.

\section{Competing interests}

The author declares that they have no competing interests.

\section{References}

1. Tillyard ARJ: Ethics review: 'Living wills' and intensive care - an overview of the American experience. Crit Care 2007, 11:219.

2. Teno J, Lynn J, Wenger N, Phillips RS, Murphy DP, Connors AF Jr, Desbians N, Filkerson W, Bellamy P, Jnaus WA: Advance directives for seriously ill hospitalized patients: effectiveness with the patient self-determination act and the SUPPORT intervention. SUPPORT Investigators. Study to Understand Prognoses and Preferences for Outcomes and Risks of Treatment. J Am Geriatr Soc 1997, 45:500-507.

3. Hanson LC, Tulsky JA, Danis M: Can clinical interventions change care at the end of life? Ann Intern Med 1997, 126:381388.

4. Fagerlin A, Schneider CE: Enough: the failure of the living will. Hastings Center Report 2004, 34:30-42.

5. Kelly DF: Critical Care Ethics: Treatment Decisions in American Hospitals. Kansas City: Sheed \& Ward 1991.

6. Bishop M: Quality of life and psychosocial adaptation to chronic illness and acquired disability: a conceptual and theoretical synthesis. J Rehabil 2005 [http://goliath.ecnext.com/ coms2/summary_0199-4389533_ITM

7. Hines SC, Glover JJ, Holley JC, Babrow AS, Badzek LA, Moss $\mathrm{AH}$ : Dialysis patients' preferences for family-based advance care planning. Ann Intern Med 2000, 133:825-828. 